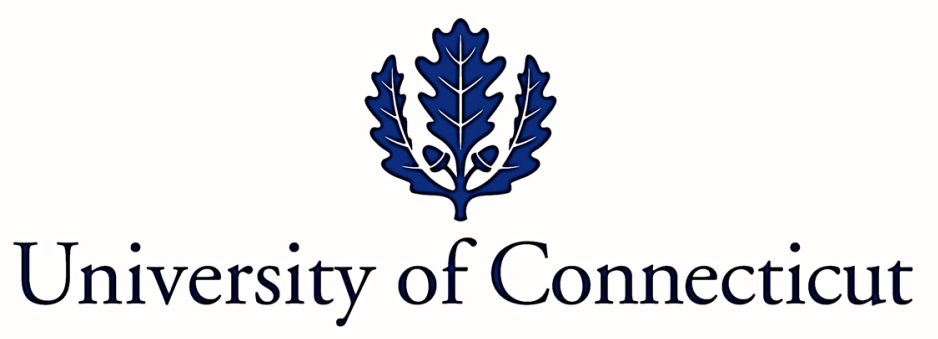

Department of Economics Working Paper Series

The State, Religion, and Freedom:

A Review Essay of Persecution \& Toleration

by

Metin M. Coşgel

University of Connecticut

Working Paper 2020-18

November 2020

365 Fairfield Way, Unit 1063

Storrs, CT 06269-1063

Phone: (860) 486-3022

Fax: (860) 486-4463

http://www.econ.uconn.edu/

This working paper is indexed in RePEc, http://repec.org 


\title{
The state, religion, and freedom: A review essay of Persecution \& toleration
}

\author{
Metin Coşgel ${ }^{1}$
}

\begin{abstract}
Persecution and Toleration offers a novel and superb analysis of the birth of religious freedom. Rather than seek an ideational account of the rise of religious freedom, Johnson and Koyama investigate changes in the institutional environment that governed the relationship between religion and the state. These changes made it in the interest of policy makers in modern Europe to grant greater religious freedom by transitioning from identity rules to impersonal laws in maintaining order. The book introduces a new thought-provoking conceptual framework that can be extended to examine the complicated history of the state's interaction with religion, comparative analysis of the relationship between state capacity and political legitimacy, and various other issues concerning the treatment of minorities and heterodox practices around the world.
\end{abstract}

Keywords Persecution and Toleration · religious freedom · state capacity · political legitimacy · legal order $\cdot$ identity rules $\cdot$ general laws $\cdot$ heterodox practices $\cdot$ minorities

JEL Classification $\mathrm{H} 10 \cdot \mathrm{K} 4 \cdot \mathrm{N} 4 \cdot \mathrm{O} 57 \cdot \mathrm{P} 48 \cdot \mathrm{Z} 12$

Metin Coşgel

metin.cosgel@uconn.edu

${ }^{1}$ Department of Economics, The University of Connecticut, Storrs, CT 06269-1063, USA. 


\section{The state, religion, and freedom: A review essay of Persecution \& toleration}

Religious freedom is a fundamental principle of liberal democracies, but with a complicated history. Despite making significant progress in advancing freedoms in the last two centuries, even modern societies committed to liberal values have at times struggled with the interpretation, implementation, and protection of religious freedom. Examples of religious persecution in recent history include the genocides of the twentieth century, continuing suppression of minorities around the world, and violent attacks on worshippers in the United States. The scope of religious freedom has also been contentious, as seen in recent debates regarding religious schools, immigration policy, and regulations of food, marriage, and clothing. These examples constantly remind us the importance, complexity, and fragility of religious liberties.

Religious freedom is at the center of the relationship between state and religion, two of the oldest institutions known in human history. In the traditional arrangement since antiquity, religion and state were typically bound together through an official faith, with significant regulations of religious beliefs and practices. Some states granted a degree of self-governance to religious minorities, but only with severe legal and physical restrictions on their movement and activities. Although the traditional arrangement slowly gave way to greater freedoms since the early modern period, the progress has involved numerous controversies, setbacks, and legal and political conflicts. To understand the complexity and fragility of religious freedom in today's societies, it is important to know how we got here and what forces hindered the development of freedom in the past as well as the historical processes that governed its eventual rise.

In Persecution and Toleration, Noel Johnson and Mark Koyama (2019) offer a novel and superb analysis of the birth of religious freedom. They use tools and insights from the recent literature on the political economy and economic history of institutions to build an innovative 
theoretical framework for analysis. Focusing on Western Europe, they use the framework to provide a coherent account of the political and economic environment that supported premodern restrictions on religious freedom. In the best tradition of social science, they use the same framework to illustrate how fundamental changes in the environment made it in the interest of policy makers to grant greater religious freedom.

Rather than seek an ideational account of the rise of religious freedom, Johnson and Koyama investigate changes in the institutional environment governing the relationship between religion and the state. In particular, they focus on the transition from identity rules to impersonal rules in the way societies can regulate the behavior of individuals and maintain order. Whereas the form or enforcement of identity rules depend on the social identity or status of individuals, such as ethnicity and religion, impersonal rules apply equally to all individuals and identities. In premodern Europe, societies typically maintained order through rules that relied on religious identity. Modern societies, by contrast, use impersonal rules and the rule of law that no longer discriminate directly on the basis of religion or other dimensions of social identity.

Under the system of identity rules that prevailed in premodern Europe, individuals had limited religious or other liberal freedoms. They could not freely practice their faith, dissent from orthodoxy, or change religious identity. Rules that relied on religious identity could allow powerful elites or the state's own agents to discriminate against, or even persecute, religious heretics and minorities. If religious dissent was tolerated, the toleration was limited and conditional on posing no threat to the social and political order. Johnson and Koyama refer to this state of affairs as a conditional toleration equilibrium.

Genuine religious freedom became possible after the sixteenth and seventeenth centuries with the rise of modern states that abandoned identity rules in favor of general rules. Although the 
system of identity rules could maintain order in the premodern period, the stability of the conditional toleration equilibrium came under attack after the fifteenth century as rulers faced more heterogenous populations and needed to adopt more general systems of revenue generation and law enforcement. By developing systems of governance that ignored social identity and religious differences, modern European states granted not just conditional toleration to dissidents and minorities, but genuine religious freedom to everyone.

To explain the transition from conditional toleration to religious freedom, Johnson and Koyama focus on the relationship between two institutional factors, namely religious legitimacy and state capacity. In their framework, these factors are alternative means for the state to acquire power for governance. Throughout history, European rulers have relied on religion to legitimize their power. ${ }^{2}$ This was particularly true for the premodern period, during which states were weak and religious authorities relatively strong enough to provide partnership for the rulers to use as a cheap and effective means to boost power. In the period after 1500, as states built greater capacity for taxation and administration, rulers could rely less on religion and more on secular sources for political legitimacy.

Given their weak fiscal and administrative capacity, premodern states could not establish genuine religious freedom. They had to rely on identity rules for governance and on religion for political legitimacy, which complemented each other. They categorized people according to religious identity, allowed rules that could discriminate against minorities, and gave concessions to religious authorities in exchange for political support and legitimacy. In addition, they did not have the means to prevent the suppression or even persecution of religious heretics and minorities,

\footnotetext{
${ }^{2}$ Researchers have recently studied legitimizing relationship between political and religious authorities to study institutions, such as state religion, and puzzling phenomena, such as bans on technology. See, for example, Coşgel and Miceli (2009), and Coşgel et al. (2012, 2018).
} 
which could happen if the conditional toleration equilibrium that prevailed broke down during times of economic crises, often set in motion by extreme weather or environmental shocks. Although the degree of discrimination and persecution varied over time and across states, the lack of religious freedom was a persistent reality of premodern Europe.

The system of identity rules started to unfold in the early modern states as a result of the Protestant Reformation and technological changes. By weakening the legitimizing powers of the Catholic Church, the Reformation dealt a major blow to the stability of the conditional toleration equilibrium. At the same time, new developments in military technology raised the cost of warfare and forced states to modernize their fiscal and administrative infrastructure in order to raise additional revenue. To stay competitive, they standardized taxes, eliminated identity rules, and introduced general rules behind laws and regulations. Altogether, these developments allowed rulers to develop other sources of legitimacy, reduce their reliance on identity rules, and build strong states capable of enforcing general rules and provide religious freedom.

Persecution and Toleration includes a thorough conceptual presentation of the main arguments and several interesting, carefully chosen, and meticulously researched examples for support and illustration. After a general discussion of the basic dichotomy between conditional toleration and religious freedom in the first chapter, Johnson and Koyama devote the next five chapters (Part 1) to detailed analysis of conditional toleration. In Chapter 2, they present a conceptual framework for examining the relationship between religion and the state in the premodern world and use it to discuss the way weak states could rely on identity rules for governance and receive legitimizing support from religious authorities. Chapter 3 examines the question of why some medieval states persecuted heretics. Whereas the early medieval states were content with the conditional toleration equilibrium and too weak to enforce religious conformity, 
the expansion of the European economy between 1000 and 1300 allowed some states to gain sufficient strength to strike a different bargain with religious authorities by championing heterodoxy and persecuting heretics in exchange for political legitimacy. In addition, the rising vulnerability of the conditional toleration equilibrium made the situation of European Jews more precarious over time, as discussed in Chapters 4-6. The persecution of the Jews rose in late medieval Europe, caused by various factors that resulted in breakdowns in the equilibrium in times of economic stress. For example, as the strength of the French state grew, the identity rules allowed rulers to engage in systematic differential treatment and persecution of the Jews beginning with the twelfth century. Starting with increased fiscal exploitation, the persecution at some point switched under Philip IV to expropriation and expulsions for short run revenue. Elsewhere, the economic stress caused by severe weather shocks and the social and political disorder that followed the Black Death raised the vulnerability of Jewish communities to persecution.

In Part 2, Johnson and Koyama turn attention to the collapse of conditional toleration and the rise of religious freedom after 1500. In Chapter 7, they examine the impact of the Reformation, how the greater religious diversity that it created shattered the conditional toleration equilibrium by causing rulers to abandon reliance on its two pillars, identity rules and religious legitimacy. When Spain, due to its unique conditions, chose the alternate path of continuing the suppression of religious differences and persecution of minorities, it failed to invest in state capacity and as a result suffered for it in long term comparative development, as discussed in Chapter 8. In Chapters 9 and 10, Johnson and Koyama follow developments in the relationship between religion and the state in France and England after 1600 and the decline in antisemitic violence in Europe during the same period. 
The final chapters of the book that comprise Part 3 are devoted to studying various implications of greater religious freedom in modern societies. This includes the falling numbers of witch trials in France after the mid-seventeenth century, the larger impact of the presence of Jewish presence on city growth in Europe after 1600, and the rise of nationalism as an alternative source of political legitimacy around the world, as discussed in Chapters 11-13. In the remaining chapters, the authors apply their arguments to the rest of the world (Middle East, China and Japan, the United States), examining the suppression of religion in the modern totalitarian states of Nazi Germany and the Soviet Union, and conclude.

Johnson and Koyama provide a wealth of evidence to support their arguments. The evidence is nicely balanced between systematic analysis of empirical data and historical narratives of people, events, and institutions. As supreme economic historians, the authors bring new data on the persecution of minorities in European history and use state of the art econometric techniques to analyze the data and uncover causal relationships. This includes using spatial data and information from climate scientists and natural experiments as proxy variables or factors that allow the identification of causal effects, such as in their estimation of the effect of economic stress on the persecution of a Jewish community. But Johnson and Koyama are eclectic in their methodological approach and equally skilled in narrating detailed case studies from European history, such as the events leading to the expulsion of the Jews in England and France in the late medieval period.

Johnson and Koyama make significant contributions to the literature on the rise of religious freedom. The traditional accounts of religious freedom typically focused on developments in intellectual history, for example as traced from the impact of the writings of Locke, Spinoza, and others. Scholars have recently offered more nuanced approaches by investigating not just 
ideational developments but also factors that made it in the interests of policy makers to accept and protect religious freedom. For example, Gill (2008) has examined the political origins of religious liberty by investigating the factors behind its adoption in some societies but not in others. These studies are typically focused on specific places and time periods. In contrast, Johnson and Koyama provide a broad and coherent political economy explanation of both the absence of religious freedom in medieval societies as well as its rise in the modern period. In addition, they put the framework up for rigorous empirical testing by systematically examining the implications of their arguments in several specific historical contexts.

Persecution and Toleration is also related to the recent developments in the literature on the economics of religion. Early pioneering contributions to this literature focused primarily on the economic analysis of religious beliefs and behavior (Iannaccone 1998). A growing literature has recently shifted attention to the legitimizing relationship between religion and the state (Coşgel and Miceli, 2009; Coşgel, Miceli, and Rubin 2012; Rubin 2017) and the evolution of this relationship over time (Coşgel, Histen, Miceli, and Yildirim 2018). Johnson and Koyama expand this literature in new directions by exploring the causes and consequences of the state's political association with religion, not just for the presence of an official religion, but for the treatment of heretics and minorities. 


\section{Figure 1 Fraction of states with official religion over time}

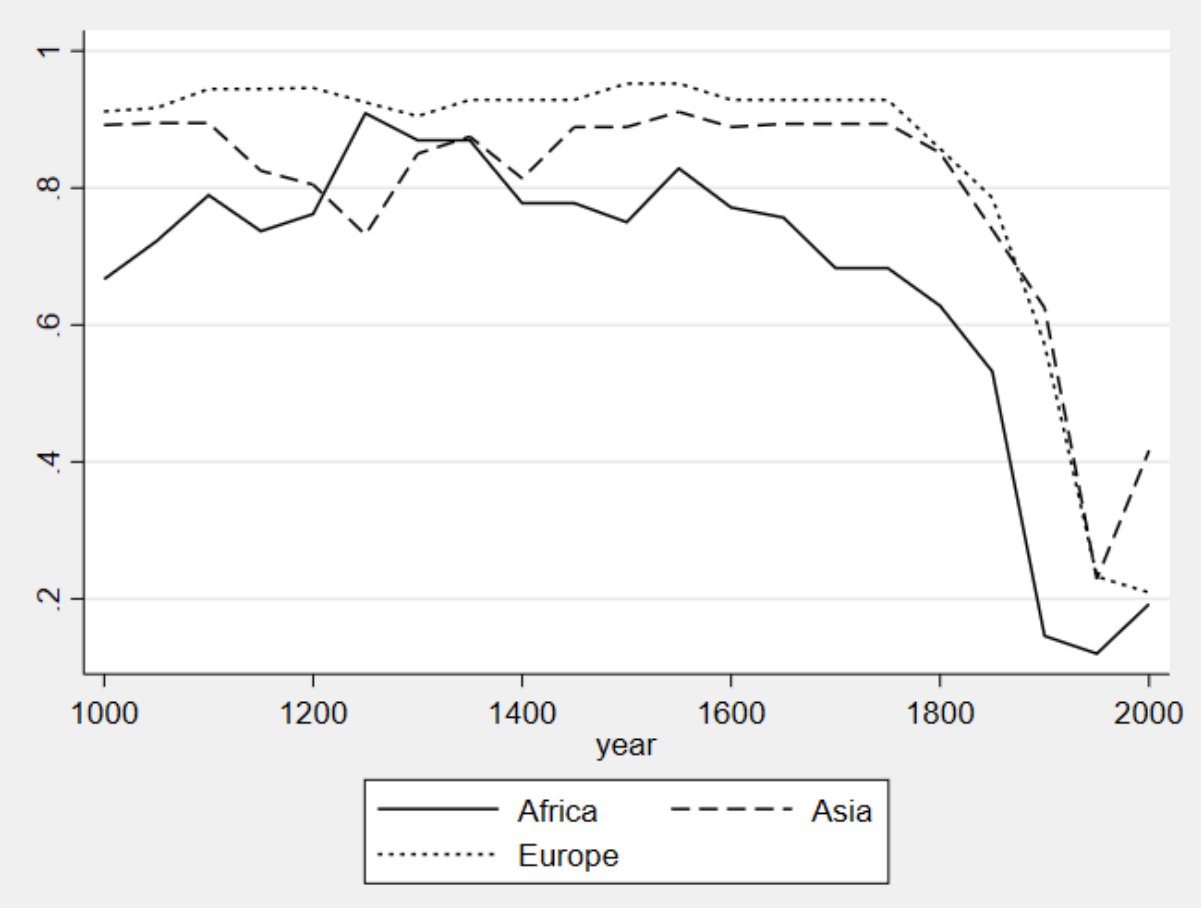

Note: Figures show the continent averages of the presence of state religion in territories occupied by today's nation states, calculated from historical data used in Coşgel et al (2018).

As seen in Figure 1, until about the last quarter of the twentieth century, trends in the average presence of state religion seem almost indistinguishable between Asia and Europe over time, and the trend in Africa followed a similar pattern despite the fraction being lower on average since about the year 1400. Given the commonalities in long term trends, the presence of state religion does not help to understand the distinct historical experience of Europe, so we need to go beyond examining monopoly rights to dominant religions, and probe deeper into the way members of other religions were treated. Indeed, by shifting the focus from state religion to religious liberties, Johnson and Koyama's work opens up new avenues for examining the evolution of the 
state's role in the treatment of religious orthodoxy and institutional changes that paved the way for the rise of religious liberty in a comparative framework since antiquity.

Johnson and Koyama's work highlights the importance of religion in economic and political history. It is directly related to the literature on the essential roles that institutions and state capacity played in the rise of modern liberal states in the West. North, Wallis, and Weingast (2009) recently described the rise of modernity as the transition from "natural states" that limited access through identity rules to "open access orders" that relied on general rules independent of social identity. Whereas North et al. did not recognize religion's role in this transition, Johnson and Koyama contribute significantly by stressing the essential role of religion in prolonging the transition by maintaining order in premodern societies. Similarly, the literature on state capacity has recently emphasized the key importance of the development of fiscal and administrative capacity in seeking the roots of the modern state. By showing the relationship between religious legitimacy and state capacity, Johnson and Koyama contribute to the literature the reason for why premodern rulers typically did not have full incentives to invest in their fiscal and administrative capacities for governance.

The simple framework developed in Persecution and Toleration is useful to examine not just the path of equilibria transition from conditional toleration to religious freedom but also the breakdowns of equilibria and deviations from the path. The framework invites numerous other interesting questions regarding the history of religious persecutions and freedoms in the world. For example, should medieval persecutions be considered as part of the conditional toleration equilibrium or as deviations from it? Similarly, what are the commonalities and differences between premodern states and today's theocracies in the persecution of orthodoxy? Other interesting questions concern the causes and implications of numerous varieties of persecutions 
and freedoms observed throughout human history and the intensity and longevity of deviations from these equilibria. Are these deviations necessarily temporary, or possible long-term departures that might result in alternate equilibria? What are the differences between persecutions by the state and other religious groups?

To examine these questions, consider first the political economy outcomes that might result from the state's interaction with religion. The outcomes in Johnson and Koyama's conceptual framework come from the realization of two basic variables, namely the type of legal order and the source of political power. States have had the option of maintaining legal order through either identity rules or general rules. Likewise, their political power has been based on either religious legitimacy or other sources of legitimacy. Combinations of these variables thus give us four conceptually distinct ways in which religion may interact with the state to maintain order and legitimize power. The first is characterized by states that use religious identity rules for legal order and receive power from religious legitimacy, the case that Johnson and Koyama call the conditional toleration equilibrium. The other case of key interest is religious freedom, characterized by states that use general rules for governance and non-religious sources for political power. The third possibility, at least theoretically, is the case of states that rely on the combination of religious identity rules but non-religious sources of legitimacy. The final possible combination is that of states that use general rules for order and religious legitimacy for political power.

The only outcomes that are self-reinforcing equilibria in Johnson and Koyama's account are conditional toleration and religious liberty, with gradual transition between them over time. Throughout much of human history, states operated in a conditional toleration equilibrium because they had weak capacity and thus needed to rely on identity rules for governance and religion for legitimacy. This balance unraveled in the early modern period as a result of the Reformation and 
developments that led to the rise of stronger states. The subsequent transition to general rules and non-religious sources of legitimacy enabled the establishment of religious freedom as the new equilibrium.

The implication of this narrative for the last two cases discussed above is that these outcomes are irrelevant and untenable, either because the states capable of receiving legitimacy from non-religious sources would not need to rely on religious identity for governance, or because the states capable of enforcing general rules would not need to rely on religion for legitimacy. This is an important implication because it denies the possibility of observing in equilibrium states that rely on religion for legitimacy and in return use general rules to promote religious uniformity by suppressing heterodox beliefs and practices. Likewise, in this line of thinking, we should not observe states that have sufficiently strong capacity to receive legitimacy from non-religious sources but that suppress heterodoxy through identity rules.

In this interpretation, religious persecutions that were observed throughout history were simply temporary deviations from equilibria caused by exogenous shocks. The conditional toleration equilibrium of premodern Europe, for example, was characterized by not just the lack of genuine religious freedom but also the lack of persistent religious persecution. As long as the heterodoxy remained within the bounds of conditions, toleration would be granted. It was a selfreinforcing equilibrium, indicating that identity rules and religious legitimacy reinforced each other. Within this structure, it was in the interest of parties to meet their end of the bargain, and only exogenous shocks would cause departures from expected behavior, such as the persecution of heretics and minorities despite meeting the conditions.

The concepts introduced by this framework are additionally useful to further distinguish among the subcategories of persecutions. Two general types of departures were possible from the 
conditional toleration equilibrium, depending on the level of state's capacity. If an exogenous shock disturbed the equilibrium, persecutions could result either as carried out by the state itself if it had the capacity to do so, or by the Church or other organized groups if the state was too weak to initiate or prevent persecutions. By including state capacity into the analysis of departures from equilibria, we can complicate the framework in a way that allows us to identify the forces that turned shocks into persecutions and the roles that the state, religious authorities, and other parties played in the process.

In the first type of departures from the conditional toleration equilibrium in premodern Europe, many instances happened because the state was too weak to prevent them. Although religious persecutions were triggered by climatic shocks or political and economic crises, the likelihood was higher in locations of weaker state presence. Johnson and Koyama's analysis of the effect of cold weather shocks on Jewish persecutions in Chapter 5, for example, shows that the risk of persecution was greater in locations that had weaker tradition of historical state presence. In the same vein, they show in Chapter 6 that state weakness in the Holy Roman Empire raised the vulnerability of the Jews to persecutions caused by the shock of the Black Death.

The other type of departures consisted of the actions of states that were sufficiently strong to persecute orthodoxy themselves. As noted above, identity rules and religious legitimacy complement each other in the conditional toleration equilibrium. A strong state could take advantage of this complementarity by implementing identity rules that brought political legitimacy from coreligionists and facilitated rent collection from other religious groups in exchange for protection and monopoly rights in trade or occupation. Strong states thus had a different role than weak states in conditional toleration equilibrium, because they had the capability to enforce toleration and prevent suppression. During times of economic crises, however, this equilibrium 
could break down, as the rulers of strong states could turn to vulnerable minorities to exact additional rents. This was the case of persecutions observed in late modern in Europe by the rulers of increasingly stronger states, as studied by Johnson and Koyama in Chapter 3.

What about religious persecution in modern states? One way to analyze the persecutions in the modern period is to apply a similar categorization and consider them as departures from the religious liberty equilibrium, in a parallel manner depending on the capacity of the state. With the rise of the liberal state after the sixteenth century, religious persecutions declined (Chapter 10), but they did not disappear. With the transition to religious liberty, modern states have generally adopted general rules and non-religious sources of legitimacy. In the first type of deviations from this norm, however, some states have occasionally faced significant challenges to their ability to enforce the rules and maintain power, especially during times of crises. In the occasional absence of functioning states, these episodes have often resulted in religious conflicts and inevitable persecution of minorities, such as the persecution of Christians and other minorities in the Middle East after the First World War and again in post-invasion Iraq.

In this interpretation, the religious persecution conducted by powerful modern states would be the second type of departures from the religious liberty equilibrium. The best-known example of this, of course, is the genocide of the Jews during the Holocaust in Nazi Germany. Despite its enormous power to enforce general rules and religious liberty, the Nazi state chose to revert to identity rules and systematically persecuted the Jews. Using the simple framework being considered here, this can be interpreted, at least in part, as the breakdown of religious liberty equilibrium in modern Europe caused by the economic crises and the chaos of the two world wars.

The question that remains is whether religious persecutions have always been in the form of random departures from equilibria caused by exogenous shocks. It would of course be somewhat 
comforting if persecutions were only random and temporary events. But this interpretation does not explain why it took a world war and a coalition of world powers to defeat the Nazis and end the Holocaust. Could the Holocaust have lasted a lot longer and spread even farther if it weren't for external interference? Neither does this approach explain the presence of modern constitutions that define a specific religion as the generic basis for all laws, nor the ongoing systematic persecution of religious deviants and minorities around the world. Legal regulations regarding the veil, for example, seem widespread, based on general rules, and unrelated to economic crises or climate shocks. These regulations systematically suppress the religious liberty of many women around the world, either by forcing them to wear hijab in some countries (e.g., Iran, Saudi Arabia) or paradoxically by requiring them to unveil in public places in certain others (e.g., Austria, France), all in the form of general rules that apply to all women regardless of religious identity.

To explain such systematic and persistent incidents of religious persecution, we may need to go back to the conceptual framework introduced earlier, specifically to the two categories of political economy outcomes omitted in Johnson and Koyama's analysis. Once again, the state's interaction with religion would in principle generate four distinct outcomes depending on the type of legal order (identity vs general rules) and the source of political power (religious vs. nonreligious legitimacy). Johnson and Koyama's analysis focused mainly on the basic transition from the conditional toleration equilibrium that relied on the combination of identity rules and religious legitimacy to the religious liberty equilibrium that relies on general rules and non-religious sources of legitimacy. The other two outcomes that might help us explain systematic religious persecution are the cases of states that rely on the combination of general rules for order and religious legitimacy for political power, and states that rely on religious identity rules but non-religious sources of legitimacy. 
Recognizing these outcomes as alternative equilibria may provide a more coherent explanation of the Holocaust, regulations of the veil, and other types of systematic religious persecutions. Consider first the case of states that rely on general rules for order and religious legitimacy for political power. Among contemporary societies, this description seems to fit the cases of Iran and Saudi Arabia, among others. In both societies, laws are general, and rulers depend heavily on religious legitimacy as the primary basis for political power. Although the laws are based on religious principles, they apply everyone equally, often independent of religious identity. Inside Saudi Arabia, for example, the (Islamic) law applies to all people regardless of their religion. Similarly, according to Iran's constitution, “all...laws and regulations must be based on Islamic criteria.” In general, this case amounts to imposing on everyone the rules and regulations derived from the religion that provides political legitimacy.

Religious laws and legitimacy in Iran and Saudi Arabia are of course important and complicated topics that deserve more thorough analysis than the synopsis given here. Notwithstanding these complications, the basic implication that stands out in both cases is the possibility of religious persecution through general laws in states that rely on religious legitimacy for political power. Any general law that is based on religious (in this case Islamic) principles (e.g., the veil) but conflicts with the principles of a minority religion would obviously be expected to result in the persecution of this minority. The simple point made here is that this corresponds to a different outcome than a temporary, shock-caused departures from the conditional toleration or religious freedom equilibria.

Modern theocracy may be an appropriate term to describe the case of states that rely on religion for legitimacy and general religious rules for order. Note that this is a very different type of outcome than the conditional toleration equilibrium, which depended on identity rules for order. 
Whereas weak states in the medieval period relied on a combination of religious legitimacy and identity rules, modern theocracies are sufficiently strong to enforce general laws to maintain order.

An important question that must be answered in recognizing this outcome as a stable equilibrium is whether state power can depend on religious legitimacy alone. If this is possible, modern theocracy may not be as anomalous as many would claim. Alternatively, one might ignore modern theocracy as a potential equilibrium if state power that depends solely on religious legitimacy does not generate adequate revenue for the state to have the ability to enforce general laws. In the case of Iran and Saudi Arabia, however, a high fraction of state revenues come from oil rents. The question may become whether oil rents or some other source of income is necessary to supplement religious legitimacy to support modern theocracy as a stable equilibrium.

The fourth and final possible outcome is that of a state that receives legitimacy from nonreligious sources but relies on identity rules for order. Religious persecution in this case can come from a strong dictatorial state that uses identity rules not to set the conditions for toleration, as was the case for the conditional toleration equilibrium of medieval period, but to identify the victims of systematic persecution. Identity rules emerge not because states lack power to enforce general rules but because states have too much power to be denied persecution. This, of course, resembles closely the case of the Holocaust under Nazi Germany. Persecution is also possible under populist governments intending to receive political support from the division of society into groups based on religion, ethnicity, national origin, and the suppression of the rights of certain minorities, such as immigrants. Once we recognize such outcomes as systematic persecutions in this category, numerous interesting questions emerge regarding other essential ingredients, such as nationalism and military power, that might be necessary to support the stability of such equilibria. 
Persecution and Tolerance is clearly an extremely insightful book about the complicated relationship between the state, religion, and freedom. Although the primary objective of Johnson and Koyama is to explain the transition from conditional toleration to religious freedom, they provide a rich conceptual framework to examine the variety of ways that the state has interacted with religion throughout history to set the rules affecting heterodox beliefs and practices. The framework is useful, not just for coherent analysis of institutional factors governing religious liberty, but to gain broader insights into the rise of the modern state in Europe, sources and consequences of state capacity, comparative analysis of liberal values and legal orders, and various other issues concerning the treatment of religious and other types of minorities. I expect the book to guide the analysis of these important matters for many years to come. 


\section{References}

Coşgel, M.M., Miceli, T.J., \& Rubin, J. (2012). The political economy of mass printing: Legitimacy and technological change in the Ottoman Empire. Journal of Comparative Economics, 40(3), 357-371.

Coşgel, M., Histen, M., Miceli, T.J., \& Yildirim, S. (2018). State and religion over time. Journal of Comparative Economics, 46(1), 20-34.

Coşgel, M., \& Miceli, T.J. (2009). State and religion. Journal of Comparative Economics, 37(3), 402-416.

Gill, A. (2008). The political origins of religious liberty. New York: Cambridge University Press.

Iannaccone, L.R. (1998). Introduction to the economics of religion. Journal of Economic Literature, 36(3), 1465-1495.

Johnson, N.D., \& Koyama, M. (2019). Persecution \& toleration: The long road to religious freedom. New York: Cambridge University Press.

North, D.C., Wallis, J.J., \& Weingast, B.R. (2009). Violence and social orders: A conceptual framework for interpreting recorded human history. New York: Cambridge University Press.

Rubin, J.T. (2017). Rulers, religion, and riches: Why the West got rich and the Middle East did not. New York: Cambridge University Press. 